\title{
Lexis
}

Journal in English Lexicology

$7 \mid 2012$

Euphemism as a Word-Formation Process

\section{The tastes and distastes of verbivores - some observations on X-phemisation in Bulgarian and English}

Alexandra Bagasheva

\section{CpenEdition}

Journals

Electronic version

URL: http://journals.openedition.org/lexis/390

DOI: 10.4000/lexis.390

ISSN: 1951-6215

Publisher

Université Jean Moulin - Lyon 3

Electronic reference

Alexandra Bagasheva, "The tastes and distastes of verbivores - some observations on X-

phemisation in Bulgarian and English », Lexis [Online], 7 | 2012, Online since 25 June 2012, connection on 07 May 2019. URL : http://journals.openedition.org/lexis/390 ; DOI : 10.4000/lexis.390

\section{(c) $\oplus \Theta \Theta$}

Lexis is licensed under a Creative Commons Attribution-NonCommercial-NoDerivatives 4.0 International License. 


\title{
The tastes and distastes of verbivores - some observations on $\mathrm{X}$-phemisation in Bulgarian and English
}

\author{
Alexandra Bagasheva ${ }^{1}$ \\ "Creative language is not a capacity \\ of special people but a special \\ capacity of all people. It shows \\ speakers as language makers and \\ not simply as language users." \\ [Carter 2004]
}

\begin{abstract}
X-phemisation constitutes a powerful appraisal resource which weaves the ethnopragmatic texture of a culture. X-phemisms constitute a special type of non-literal language which capitalizes on all other possible types of non-literal language and the creative exploitation of phonetic-based word play. The main aim in the present paper is to elaborate on a hypothesis of X-phemisation via lexical extension (recruitment) as involving the mechanism of nominal metaphor at the conceptual level. This mechanism involves reframing of the vehicle (target) denotatum with an accompanying rearrangement in salience rating in the arising ad hoc concept resulting from blending the frames of the topic and vehicle denotata. This stereotype-violating mechanism reveals the power of human ingenuity at the deepest level of linguistic creativity. The ad hoc X-phemistic concept blends in an axiologically motivated manner the contextually relevant features of both denotata in a salience-constrained perceptually and evaluatively ordered set of features, triggered by the initial anchoring via the topic denotatum evoked by the actual lexical expression (the vehicle lexical concept). $\mathrm{X}$-phemisms (from fully lexicalized ones to highly innovative/artful ones) and $\mathrm{X}$-phemisation as an epiphenomenal occurrence in online linguistic interaction are seen as constituting a special subsystem in the appraisal resources of a language. This subsystem has special status with its high creativity and figurativity. Figurativity captures simultaneously the emergent, dynamic nature of X-phemisms and their grounding in stable conceptual metaphoric structures (in terms of strategies for their production/comprehension). Despite the diversity of X-phemism types (both in terms of their overall pragmatic effect) and the nature of their origin (resulting from substitution, lexical creativity, metaphoric transfers, phonetic innovation, word play, etc.), $\mathrm{X}$-phemisms constitute a complex uniform catgory whose complexity can only be adequately studied in the framework of interactional cognitive studies, where the emotional brain is also subsumed under 'cognitive'.
\end{abstract}

Key words: recruitment X-phemisms, reframing, stereotypes, appraisal resources

\footnotetext{
${ }^{1}$ Sofia University, Department of British and American Studies: abagasheva@gmail.com
} 


\section{Introduction}

X-phemisms constitute a category of non-literal forms in their own right. Some of them piggyback on other categories of nonliteral forms (such as metaphors, metonymies, irony, idioms, hyperbobles, litotes, etc.), others exploiting different meaning-creating strategies (alliterations, sound dis/associations, etc.) may even be perceived as literal language. Despite the cognitive complexities involved in differentiating between literal and non-literal, X-phemisms of all types are characterized by projecting the speaker as having taken a specific evaluative stance ${ }^{2}$. X-phemisms always involve attitudinal marking and in their cognitive and pragmatic effects they constitute a uniform category despite the ingenuity in their creation and the diverse types they realize (for an overview of the types of X-phemisms see Allan and Burridge 1988, 1992, 2006, Crespo Fernández 2008; Gomez 2009 among others). X-phemisms are unified by a constant among all their rich pragmatic accomplishments - an implicit, cancelable, yet clearly detectable attitudinal stance (irrespective of the intentions of the speaker and the degree of self-awareness projected in the production of an X-phemism). Even if the speaker has engaged in X-phemistic verbal behavior inadvertently, the Xphemism functions as an anchor for inferential and interpretative strategies and affects the perception of both the denonantum and the speaker.

Reliable generalizability is difficult with X-phemisms as they embody the platitude, to borrow Barr and Keysar' words [2005: 22] that "meaning is underdetermined in the sense that the same string of words can convey anything from a benign comment to vicious sarcasm". It is rather challenging to come up with a uniform fruitful heuristic for the study of tinted language. Tinted language can only be studied in view of the numerous socio-cultural variables which anchor its value along the benign-vicious scale. However, as no exhaustive list of socio-cultural variables that might directly correlate with X-phemisms has been compiled and since the interplay between types of nonliteral language and determining socio-cultural variables is extremely involved and varied, in this paper the use of X-phemisation is discussed as broadly couched in a multifaceted context which is viewed as a more or less coherent whole, without expressly defining each relevant variable which might have causal effects on any features of the X-phemism. Only when a specific variable is considered of extraordinary importance and is identified as clearly acting as a causal agent for a particular feature of an X-phemism will it be singly named and discussed as and if appropriate. Consequently, unless expressly stated otherwise, throughout the current paper interactants who are able to recognize an X-phemism as such are assumed to be prototypically generally affected in terms of their emotional response; their attitude toward the speaker, another person, the target referent or some issue. At least in the majority of cases of X-phemistic verbal use, the speaker is perceived as having projected a certain attitude and is perceived as having taken a particular appraisal stance. RecruitmentX-phemisms forma

\footnotetext{
2 Stance is used here as defined by Du Bois "a public act by a social actor, achieved through overt means, of evaluation, positioning, and alignment, with respect to any salient dimension of the sociocultural landscape" [Dubois 2002]. This definition is harmonious with Martin's [Martin 2001] understanding of the interplay between evaluation and appraisal and the taking of stance in relation to these.
} 
special part of the appraisal resources of a language. With recruitment X-phemisms the representational dimension of meaning is superceded by the stance-taking appraisal one as the point of entry into a concept, i.e. the mode of signification, is changed. This relates to the distribution of effort between rhetoric and desing ${ }^{3}$ in achieving the overall communicative effect in interaction. Thus recruitment X-phemisms surface with default engagement value which is difficult to cancel.

As any phenomenon involving syntax or semantics and concerning pragmatics are made insurmountably artificial if not studied in situ, the present paper dicusses either fully lexicalized X-phemisms (whose contextual uniqueness has been reduced to more or less predictable variability) or absolutely novel ones with the general public as intended listener, in order for heightened authenticity to be achieved (relying predominantly on observational methodologies).

Among the plethora of X-phemistic types (classified in terms of the creative process involved in their coming into being - e.g. figures, flippancies, remodellings, metaphors, substitutions, sound symbolism/phonesthesia, etc.), the X-phemisms defined by Allan and Burridge 1991 as "cross-varietal synonyms" are the focus of the present discussion. Instead of being recognized as synonyms, X-phemisms of this type are interpreted as "recruitment" X-phemisms. The choice is not simply a matter of terminological preference. The term "recruitment" more precisely presents the fact that X-phemisms are not simply cross-varietal synonyms as they always involve the dimension of affect and thus constitute neo-semanticisms with specific socio-cognitive features, not simply contextual synonyms with differential stylistic effect - they encode the affect dimension and it becomes part of their multidimensional semantic constitution. Besides "recruitment X-phemisms" (to be explained in part 3), idiomatic X-phemisms, Xphemistic verbs for orthophemistic activities, and X-phemistic diminuitives are discussed (in parts 4 , and 5 and 6 respectively).

The data have been excerpted from three corpus-based dicitionaries (two editions of the series New words in Bulgarian 2001 and 2010 and a Bulgarian-English dictionary of slang 2010), from the newspapers "Trud", "24 chasa" and "Dnevnik" in Bulgaria, from $O E D$ and Holder's dictionary of euphemisms (2007). As a consequence, the majority of Xphemisms discussed are fully lexicalized or semi-lexicalised. A notable exception is the creative, contextual euphemistic dysphemism discussed in 3.2.

The methodology applied is observational (not experimental), and hypotheticodeductive. The analysis makes use of the achievements of Conceptual Metaphor Theory (CMT - Lakoff and Johnson 1980,1999), Conceptual Blending Theory (CBT - Fauconnier and Turner 2002), Theory of Lexical Concepts and Cognitive Models (LCCM theory Evans 2007, 2009), psycholinguistic studies of non-literal language and human categorization (Colston and Katz 2005; McGlone et al. 1994; Glucksberg 2001), socio-

\footnotetext{
3 Kress [2010: 49] distinguishes between representation and communication as two distinct social practices. Both are involved in linguistic interaction. Rhetoric is oriented toward the social or political dimensions of communication, while design is oriented to the semiotic, i.e. representational dimension of interaction. In choosing a specific lexical item a speaker commits his/herself to an "aptness" consideration, how fit a given signifier is to be the expression of a particular meaning. A lexical item is a perceptual prompt offered by the speaker for the way a referent is to be approached. It functions as a blue-print for (re)arranging the properties of the referent in terms of salience. Thus the invitation for rearrangement functions as indicator of stance-taking.
} 
cognitive studies of stereotypes (Schneider 2004; Hamilton et al. 1994) and the findings of X-phemisms specialists (Allan and Burridge 2006, Crespo Fernández 2008, Gomez 2009).

A terminological and methodological digression is in order. Following Richards (1936) and Glucksberg (2001) in understanding nominal metaphors, in the present paper the following terms will be utilized: "topic" as the referent of the X-phemism and "vehicle" as the predicate noun, which provides the "ground" (of the metaphor, if such is involved in the origin of the X-phemism) or the anchor for the ad hoc conceptualization. The ground is the new information provided by the vehicle, that is, the property or properties of the vehicle that are assumed or at least projected as characterizing the (metaphor) topic. Throughout the paper target and topic will be used interchangeably, as will be vehicle and source. This seeming inconsistency is necessitated by the fact that the latter terms are better suited to X-phemisms which result from conceptual metaphors and which have been lexicalized (conventionalized) to a higher degree, while the former more adequately describe the process in creating novel X-phemisms. Nominal metaphor is assumed to instantiate the cognitive mechanisms underlying recruitment X-phemisation. No matter if nominal metaphor is actually used in the linguistic encoding in the communicative exchange, the mechanism of category (and attribute) reframing driving nominal metaphor underlies and governs the conceptual processes implicated in X-phemisation (at least as far as recruitment and figurative (idiomatic) X-phemisms are concerned). In the theory of nominal (referential) metaphor, topic is considered to be the "given" information (Clark and Haviland 1977). In acknowledging the operationality of nominal metaphor as the conceptual mechanism underlying X-phemisation, it should expressely be noted that the vehicle (source) denotatum presented directly with its lexical concept profiles the conceptualization and provides the trigger for reframing the attributes set of the topic (target) denotatum. Xphemisms are exemplar cases of what Evans [2010: 604] defines as linguistic metaphor - "an utterance-specific metaphoric conception". For him, linguistic metaphors, which are elements of front-stage processing realizing presentational design and differ from conceptual metaphors as elements of back-stage cognition, reside in and emerge "from a situated (and hence contextualised) instance of language use. Linguistic metaphors may draw upon non-linguistic knowledge (including conceptual metaphors)" [ibid.]. The specifics of X-phemisation establishes it as a complex process employing the mechanism of metaphtonymy ${ }^{4}$ which collapses the joint effects of the two conceptual operations of metaphor and metonymy without predicating any sequential or causal ordering between the two and manages to capture their intricate interplay. By their mere coming into being X-phemisms represent "illocutionary metonymies" as defined by Panther and Thornburg $(2003,2007)$ and invite the perforce creation of a single referentially contiguous domain matrix as frame against which the target denotatum (referent) is to be perceived and conceptualized in an ad hoc conceptual structure.

\footnotetext{
4 Metaphtonymy is used as a cover term to name processes of conceptual (and/or referential) metaphors and metonymies. It was coined by Goossens and defined as "a mere cover term which should help to increase our awareness of the fact that metaphor and metony can be intertwined" [Goossens 2003: 350].
} 


\section{X-phemisms as an appraisal resource}

This seeming complication only comes to illustrate that the study of X-phemisms as linguistic items and of X-phemisation as a complex phenomenon involving linguistic, socio-cognitive, discursive and social psychological dimensions is extremely challenging. As Ricoeur [1981: 340] has warned us "language could extend itself to its very limits forever discovering new resonances within itself" and X-phemisation plays an important role in amplifying these resonances which are intricately interwoven with various linguistic processes, such as semantic and lexical changes for example, metaphtonomy extension through creating novel modifications of conceptual metaphors and/or metonymys, etc. This rich system of "resonances" belongs to the appraisal resources of a language, even though it cannot be straightjacketed into any of the well-differentiated systems thereof. Appraisal language of affect relates to the expression of the speaker's opinion along the good/bad parameter. The wide range of interpersonal resources known by the blanket term "appraisal" resources interact intricately with X-phemisation as they specialize in the expression of affect and emotion, which are often difficult to differentiate among. The semantics of evalutaion involves according to Martin [2000: 144] a specification of "how the interlocutors are feeling, the judgements they make, and the value they place on the various phenomena in their experience". In X-phemisation interactants' affect and judgement attitudes are implicitly encoded and this makes Xphemisation a central resource of the appraisal system. X-phemisation is closely linked with the "potential of language to express different emotions and degrees of emotional intensity" [Ochs 1989: 1]. In systemic functional accounts X-phemisms (subsumed under technical and specialized lexis, taboo lexis and swearing, slang and naming (Halliday 1994, Martin 2000) are classified under the system of involvment and are considererd non-gradable. However X-phemisation is a gradable phenomeonon as various X-phemisms can have different values in different communicative exchanges and more importantly X-phemisms for the same denotatum can be graded along the attitudinal/judgmental connotations encoded in them (e.g. spineless, weak-kneed, which illustrate the concept of recruitment dysphemisms, express different degrees of disapproval judgements in relation to the orthophemistic indecisive, irresolute).

This non-referentially evaluative semantics has led to the establishment of Xphemisation in all cultures as a powerful ecological niche within the appraisal resources of a language. The appraisal system avails of both explicit (descriptive) evaluative expressions and masked (implicit) ones. More significantly, appraisal collapses pure emotion and cognitive evaluation or as Malrieu [1999: 50] has formulated it, "[e]valuation is precisely one of the ways in which culture gives a shape to our affects and it should therefore be perceived as a point of articulation between affects and cognition". X-phemisms with their amalgamation of cognition (conceptualization and reconceptualization) and direct tapping into emotional sensitivities provides the verbiage articulating evaluation via their colouring rhetoric and ample design 5 .

\footnotetext{
5 Rhetoric and design here refer to Gunther Kress' social semiotic approach to contemporary communication [Kress 2010: 26], according to which "the world of meaning ... is marked by instability and provisionality, every event of communication is unpredictable in its form, structure and its 'unfolding". "The rhetor as maker of a message now makes an assessment of all aspects of the
} 
"Rhetoric" in relation to X-phemisation identifies the fine nuances of (implicit) evaluation, while "design" relates to the specific presentational mode chosen in the realization of X-phemisms. The presentational mode chosen for an X-phemism has direct influence on the interpretation of the denotatum and has the power to override the essence of the denotatum and impinge on its different properties. The dysphemism for "sinning" backsliding does not only offer an alternative name, presenting "sinning" (which is referentialy judgmental) as "physical movement backwards" only indirectly expresses judgement by capitalizing on the conceptual metaphor LIFE IS A JOURNEY and the implicational complex of lower level metaphors associated with it. In comparison to "sinning", "backsliding" with its figurative presentational mode invites the listener to reassess sinning and its consequences in more physical terms and this perceptually aggrevates the negative judgement passed on this human activity. It also stripps the activity from its religious implications and broadens the category. Thus X-phemisms challenge standardized referentially judgmental values and overcome the highly schemtazied, conventionalized viewing of the world through languge. This viewing is what Slobin [2005: 13] has termed the "more static way of language use" of adults, which arises out of getting accustomed "to the schematics of language" [ibid.] and accounts for the existence of stereotypical frames associated with specific referents. The more interactive framing of referents characteristic of X-phemisms revives the more interactive, inventive and playful exploitation of the "rules of the game". X-phemisms are thus tied up with the "heuristic" or "I explore" function which Halliday (1975) identified for language. This heuristic function interacts with the imaginative one, to produce the highly effective impact of reconceptualization as an appraisal resource. X-phemisation plays a pivotal role in value shifts on the basis of the joint attention thesis (Tomasello 2003a; 2003b). Recruitment X-phemisms offer alternative frames and thus window the attention of interactants to previously unnoticed or considered insignificant features of the topic referent, or introduce new ones. When they become fully lexicalized, such Xphemisms lose much of their attentional appeal and shed much of their interactive and conceptual creativity; instead they (or rather their use) acquire a predominantly indexing function positioning interactants in particular sociolinguistic categories. Lexicalization is tightly linked with stored mutual knowledge on the part of interactants and the degree of novelty will depend on the socio-cultural and experiental backgrounds of the interactants in a given communicative exchange. The degree of novelty plays a role in identifying the directedness of dysphemisms towards the referentor towards the interactant. There is a tendency for novel dysphemisms are perceived as offensive towards the referent, while fully lexicalized and widely known dysphemisms are more likely to exercise an offensive effect towards the interactant as they have acquired a degree of stereotypicality which guarantees the predominance of their indexing function. From a purely psychological point of view, if a speaker chooses to present a referent in discourse through a fully lexicalized dysphemism (such as пълно дърво [palno darvo, "absolute tree", somebody/something dull, useless orincompetent]) this is easily interpreted as expressing a negative or at least slithing attitude to the

communicational situation" [ibid.] and resorts to designing the presentation of meaning intentions and knowledge by exploiting all available semiotic resources, where menaing and forms mutually permeate one another. 
interactant(s) as both parties engaged in the communicative exchange are aware of the judgmental value of a fully lexicalized dysphemism. Engaging the listener in such a mode of discourse implies that the listener is not considered as projecting an authority to be reckoned with, so both social and linguistic interdiction are loosened. In parallel to using a honorific marker (if there is such a system in a language), the choice of a lexicalized dysphemism might be recognized as one of these indexes which Silverstein ${ }^{6}$ (1976) called "maximally creative". Besides signaling solidarity, the use of a lexicalized dysphemism indicates lowering of the discourses which implicates the listener as belonging to that realm of the order of discourses. If a dysphemism is novel, there is always the possibility for its representational and connotative functions to suppress its indexing function (to both referent and interactant) for lack of associations with other contexts. The novelty of a dysphemism (for lack of other implicated contexts and polyphonous voices) guarantees its indexing 'innocence' in relation to the referent? When I heard for the first time a student in class describe the tape-recorder as тояга [toyaga, cudgel, bludgeon], I didn't inter pret his verbal behavior as intentionally negative towards me. I had never heard this expression and strained my mind to uncover the intended meaning. When I learned that it means the same as the lexicalized пълно дърво I interpreted this use as indicating the poor state of the tape recorder and the low quality it produced in class and the student's infuriation with these facts. When later I heard a colleague of mine use this as a description of a novel I felt a bit dejected as I perceived this verbal choice as indexing me as incapable of following a more elaborate and argumented opinion of a book.

The specific appraisal effect of X-phemisms is the projection of a particular speaker's persona who takes a distinct evaluative stance (no matter if the reasoning mind has purposefully chosen the respective expression). This attitudinal positioning is achieved at the lexical level but the lexical expressions used have masked attitudinal values, i.e. they have only connotative evaluative values and are not referentially evaluative (they are recruited for the evaluative lexicon on the basis of the X-phemistic effects they produce on the basis of the denotative reframing they engender). For the greater part Xphemistic expressions encode adopted appraisal stances, in which it is difficult to distinguish between the separate evaluative dimensions - judgment, affect and appreciation. Leading among these stances is the affectual one because this is what the listener experiences in perceiving the X-phemism.

$\mathrm{X}$-phemisms are not simply cross-varietal synonyms as each X-phemistic expression produces unique cognitive effects. Resulting from communicatively represented social esteem or social sanction X-phemisms, fill in an ecological niche in the evaluative resources of language as X-phemisation naturalises a specific listener's position as far as evaluation is concerned as it is recognized by Martin (2000: 142-143) as fairly directive

\footnotetext{
6 In Silverstein's indexiality approach to culture "the communicative force of culture works not only in representing aspects of reality, but also in connecting individuals, groups, situations, objects with other individuals, groups, situations, and objects or, more generally, with other contexts" [Duranti 1997: 35].

7 According to Agha (n.d.) speech is personified in the sense that variations in lexical repertoire are linked to social classifications of interactants. "Once speech is personified in this way the deployment of particular slang repertoires makes possible both the performance of normative identities and the tropic manipulation of speaker persona through various types of displaced usages" [Agha n.d.: 5]. In this way the emergent speaker-addressee alignment projected by a speaker indexes the listener as well.
} 
in the kinds of attitude it wants the listener's to share. The concepts of evaluation (as a central interpersonal resource in language), of connotation and X-phemisation are intricately interrelated and sharp boundaries are hard to draw. Appraisal is understood here as defined by Martin [2000: 145] as "the semantic resources used to negotiate emotions, judgements, and valuations, alongside resources for amplifying and engaging with these evaluations". X-phemisms are special among appraisal resources as they are not referentially evaluative (unlike referentially evaluative adjectives - good, nasty, etc.) and combine cognitive and affective aspects. Admittedly, one is tempted to agree with Voloshinov [1973: 105] that, "[n]o utterance can be put together without value judgement. Every utterance is above all an evaluative orientation. Therefore, each element in a living utterance not only has a meaning but also has a value" (emphasis in the original). However lexical items have different modes of signification, i.e. provide different routes of access to conceptual content. In some evaluation is direct and is a defaultfeature of the conceptual contentand part of the representational function of the lexical item (good, pleasant, captivating, etc.), i.e. evaluation is part of their descriptive dimension. In others evaluation is secondary or derived via some associative mechanism, but their mode of signification triggers first and foremost a seemingly untinted description (e.g. fat, made). In the latter's lexical concept center-stage is preserved for describing features of objective properties ( fat - body size; made - origin). Euphemisms are by definition evaluative, but this is secondary, relational evaluation, arising out of the choice of the particular lexical item which in its primary mode of signification doesn't have the cognitive motivation to evaluate. The fact that this lexical concepthas been chosen in particular creates the marked evaluation by way of contrast with a neutral or negative lexical item. The euphemisms fully-figured and hand-crafted acquire their positive evaluative charge indirectly by exploiting the effect of elevation of indirect speech. As Malrieu [1999: 51] articulates the intertwining of cognition and affect, "evaluation either refers to a cognitive appraisal of a phenomenon or to the cognitive theory of processes of evaluation involving both cognitive and affective aspects." Referential as opposed to affective evaluation is distinguished for its primary cognitive appraisal. Among the affective aspects a central place is occupied by perceptual behaviours as affect is the perceptually motivated representation in the emotional brain. X-phemistic linguistic behavior targets or achieves control over the perceptual behavior of interlocutors. This underlies the distinction which can be drawn between overtly evaluative language (perfect, gorgeous, disgusting, etc.) and covertly evaluative language (chicken-livered, duck-brained, gutless, etc.). Denotatively (explicitly) evaluative language (language whose primary function is to describe evaluative judgements) and connotatively evaluative language (where evaluation stems from the artful interplay between rhetoric and design and is heavily dependent on the (re)presentational mode of accessing the referent) rely on different cognitive processes for achieving attitudinal response in interactants. As Martin and White [2005: 64] reveal, "ideational meaning can be used not just to invite but to provoke an attitudinal response" which is rightfully considered "one function of lexical metaphor" [ibid.]. In fully lexicalized X-phemisms the two types of evaluation are amalgamated into one. Yet, despite acquiring denotatively evaluative properties, such expressions keep piggybacking on the literal meaning of the lexical item chosen for presentation and thus evaluation is masked behind socially censored linguistic choices. 
The recognition of the important role played by the presentational mode is harmonious with the acknowledgment of the significance of perceptually motivated affect. As Smith and Semin [2007: 134] remind us,

[R]esearchers should acknowledge that adaptive cognition involves perceptualmotor loops that pass through the environment rather than being mostly implemented by autonomous inner processes. Strong support for this principle comes from recent work placing sensory and motor information at the heart of both conceptual representations in general and particular social-cognitive processes like understanding other people. (Emphasis added)

The understanding that socio-cognitive processes hinge on perceptual in situ triggers of meaning generation leads to the need to reassess our notions of concepts as stable structures and aknowledge the plasticity of categorization/conceptualization. This plasticity can fruitfully be operationalized in terms of ad hoc concept creation. Xphemisation like metaphoric (or more generally figurative) language hinges on ad hoc concept creation (for a book-length treatment of the role of ad hoc concepts in nonliteral language creation/comprehension see Tendahl 2009). Creativity at this level boils down to the choice of recruiting stereotyped concepts to be refined in the construction of the ad hoc concept. Such an approach to conceptualization reveals the depth of creativity involved in X-phemistic linguistic behavior.

\section{Creativity and $X$-phemisation}

\subsection{Creativity as reframing}

The issue of creativity in linguistic interaction has recently attracted enviable attention (Chomsky 1980, De Beaugrande 1985, Kearney 1998, Zawada 2006, Langlot 2006, Carter 2004, Munat 2007, 2010, etc.). As in all areas of investigating human ingenuity, the issue is wrought in controversies. Definitions of creativity range from rule-goverened recursion to idiosyncratic poetic creations and special ways with words. Hopefully the profusion of research on linguistic creativity will prove Chomsky [1980: 222-223] wrong in his prophecy that "the creative use of language is a mystery that eludes our intellectual grasp." For the purposes of the present argument, the comprehensive definition of linguistic creativity provided by Zawada [2006: 236-237] is adopted:

(Linguistic) Creativity is an essential and pervasive, but multi-dimensional characteristic of all human beings (irrespective of age, education, intelligence, social status or artistic bent). Linguistic creativity is primarily the activity of making new meaning by a speaker (in the broadest sense of the user of language in all forms and in all mediums), and the recreation and re-interpretation of meaning (s) by a receiver. Linguistic creativity is secondarily observable as a feature or product in a language. Linguistic creativity is a graded phenomenon ranging from the more conventional and predictable to the less conventional and unpredictable, and it is manifested in all domains of language (lexis, grammar, text and discourse), the results of which may 
or may not become conventionalised and therefore entrenched in a particular language. (Emphasis added)

In view of this definition, recruitment X-phemisms are doubly creative because besides surfacing as new semanticisms (making new meanings), they orchestrate the attitudinal dimension in the semantic prosodies of linguistic expressions in the interpretative strategies of the interactants. As such X-phemisms become prototypical examples of lexicogenetic mechanisms ${ }^{8}$ of semantic change. As such they are characterized by creativity, which is understood as a "bisociative process" or the deliberate connecting of two previously unrelated "matrices of thought". The two unrelated matrices of thought originate from the stereotypically construed nature of the denotatum and how it is framed in a particular communicative exchange. According to Koestler [1964: 119] creativity includes "the displacement of attention to something not previously noted, which was irrelevant in the old and is relevant in the new context; the discovery of hidden analogies as a result." Thus the process of X-phemisation appears highly creative at the level of conceptualization or framing of denotata ${ }^{9}$. X-phemisation achieves an attention switch which is realized against the background of linguistic stereotyping. Just as stereotypes are, according to Blumentritt and Heredia [2005: 261-262] "cognitive frameworks that consist of beliefs and generalizations about perceived typical characteristics for certain social groups", so lexicalizations ${ }^{10}$ in relation to any kind of denotata are stereotyping frames which activate particular cognitive schemas with certain properties of the denotatum and an underlying emotive-evaluative associative mark. X-phemistic expressions re-frame denotata and establish alternative frames by imposing a different anchoring in the ad hoc conceptualization process involved in online linguistic interaction. X-phemisms function as cues to semantic priming with heightened emotive-evaluative results. This priming is based on contingent metapthonymic relations. Conceptual metaphors themselves are not X-phemistically specified, even though certain source domains used as maps to the nature/topology of more conceptually demanding domains might show some proclivity towards predominantly dysphemistic or predominantly euphemistic prompting. On the whole, as Crespo Fernández [2008: 97] revealingly argues:

certain values are given priority in the metaphorical structuring of a given concept, the filter of metaphorical conceptualization through which reality is presented provides us with a partial understanding of the concept, masking or revealing particular aspects of the topic being dealt with, a process which makes conceptual

\footnotetext{
8 "Onomasiological (or 'lexicogenetic') mechanisms, conversely, involve changes through which a concept, regardless of whether or not it has previously been lexicalized, comes to be expressed by a new or alternative lexical item." [Geeraerts 2010: 26]

9 This conception is fully in keeping with Gómez's (2009) attenuation and reinforcement developments of alternative conceptualizations of interdicted areas in euphemisation. In addition to the reinforcement of forbidden areas in dysphemisms, in the present paper it is claimed that dysphemistic reconceptualization is possible in cases of conceptual orthophemy (i.e. attitudinally neutral areas).

10 By lexicalization here is meant the packaging of conceptual content via a lexical concept into a conventionalized lexical expression (as opposed to encoding via grammatical means, discourse structuring or other more elaborate expressive strategies).
} 
metaphors readily accessible for euphemistic or dysphemistic reference respectively.

To further stretch the applicability of conceptual metaphor in human life, we will use them here to make more palpable the cognitive processes underlying recruitment Xphemisation. Such a move of exploiting conceptual metaphors as theoretical (metalinguistic) vehicles is justifiable in view of their being recognized by Evans [2010: 603] as being "concerned with backstage cognition - the role of the non-linguistic conceptual processes that facilitate meaning construction behind the scenes", and not as statements from a theory about understanding metaphor in language. The complex processes of X-phemisation instantiate the conceptual metaphor CREATIVITY IS SEEING IN DIFFERENT LIGHT. The basic scenario revealing the nature of reframing in X-phemisation can be captured in another well-established conceptual metaphor CREATING IS MAKING VISIBLE. The essence of reframing in X-phemisation is offering a perspective for viewing the referentfrom the perspective of its presupposed similarity with the referent named by the lexical concept used as a new semanticism. It also implicates the overriding metaphor IDEAS ARE PERCEPTIONS. And last but not least, the mechanism of nominal metaphor underlying recruitment X-phemisms is accomplished via THE COMPARISON OF PROPERTIES IS THE COMPARISON OF PHYSICAL PROPERTIES. When combined as principles of backstage cognition and as metalinguistic models these conceptual metaphors summarise the backstage cognitive processes driving X-phemisation. In X-phemistic linguistic behavior (as defined by Allan and Burridge 2006) the X-phemistic expressions as instructional prompts invite a different, non-stereotypical conceptualization of the denotatum. This conceptualization may or may not involve conceptual metaphor (Xphemistic verbs only rarely involve and X-phemistic diminutives never involve conceptual metaphors). What makes X-phemisms special among the numerous linguistic realizations of conceptual metaphors is the fact that the former are not driven by the economy principle of borrowing the conceptual representations of concrete concepts for the representation of more abstract ones. In X-phemisation it is often the case that the target and the source share the same dgree of concreteness. The motivation behind the creative application of conceptual metaphor in the creation or use of X-phemisms is the realization of an attitudinal switch in keeping with the hypothesis of joint attentional behavior (Tomasello 2003a, 2003b) and the hypothesis that the mechanism of nominal metaphor underlies conceptual processes in $\mathrm{X}$ phemisation.

Actually, the cognitive processes resulting in X-phemisation are consistent with Murphy's (1996) weak version of the role of conceptual metaphor for representations in the mind and their linguistic encoding. X-phemisms provide pragmatically motivated reconceptualizations responsible for the semantic prosodical marking of a verbal exchange. In X-phemistic categorization the salience and centrality of features are rearranged, i.e. a different set of features is identified as central for categorization and promoted as sufficient for recognizing the referent as a member of the category we are assigning it to. We judge the referent against a situationally relevant prototype and the ad hoc concept we project of it accumulates features which are judgementally (attitudinally) motivated. As social categories are by definition value-laden (Schneider 2004) and folk theories underlie categorization, it is obvious that in situ 
conceptualization involves social recategorization as a feature X-phemistic categories, which modulate the values associated with a certain referent, reframing it in a way that will evoke certain category ascriptions that are situationally relevant and have specific axiological marking. X-phemisation involves the creation of compound categories which frame the referent in unexpected but revealing ways.

This aspect of the conceptual creativity of X-phemisation is best operationalized as the emergent properties of the referent which is conceptualized ad hoc as a compound category. In its turn the notion of the compound ad hoc concept operationalizes Crespo Fernández's insight about the bidirectionality of lexicalized conceptual metaphor within the framework of Black's Interactive Theory of metaphor. In Crespo Fernández's [2008: 101] own words,

it can be deduced that using metaphors with a lexicalized sexual meaning in discourse does not only involve a projection from the source domain onto the target domain, since the target domain may also be projected onto the source domain.

The phenomenon of bidirectionality is not restricted to lexicalized sexual taboos but has a much wider scope, underlying numerous recruitment X-phemisms as part of the compounding conceptual mechanism actualized in reframing. There frequently arise contexts in which ambiguity is difficult to resolve between the metaphoric (target) reading of an X-phemism and the literal (source) meaning of actualized lexicalization. Pfaff, Gibbs and Johnson [1997: 61-62] provide evidence that the mitigating or offensive value of X-phemisms is easier to comprehend if there is a conceptual match between these and the context,

Our contention is that a speaker should consider one X-phemism [euphemism or dysphemism] more appropriate than another in a certain context because he is conceptualizing that context metaphorically... contexts can provide people with metaphorical concepts that influence the appropriateness or ease of interpretation of the X-phemism by cueing them to its metaphorical meaning.

Той е голям лапач [Тоу е golyam lapach, He is a real gobbler] describes a person who loves eating heartily when used in non-political or criminal contexts. When лanay appeared as the name of a special police operation for financial criminals and occupied the front pages of printed media (e.g. the newspaper Dnevnik 23 March 2010) for a week or so, the lexical item acquired strongly dysphemistic properties, which have now overridden its original, literal meaning. It is now understood as He is one of the real spongers/moochers/criminals and if a speaker has intended it to apply with its literal meaning, they resort to repeating the lexical item to indicate that it has to be understood in its original meaning relating to food consumption. The dysphemism lexicalizes the GETTING IS EATING conceptual metaphor. When used in the media (to report for example the special police operation for arresting people involved in schemes for stealing VAT from the state), it is understood exclusively in its dysphemistic meaning. When used in everyday contexts in family settings, it remains ambiguous because the target dysphemistic meaning is so salient in terms of the socio-political situation that it has been projected onto the initial source and is likely to be ousted out in its original 
meaning to be replaced by the more generic noun associated with the consumption of food ядач [yadach, a person who eats a lot and loves to eat]. Such examples (and there a plenty of them) point to the fact that X-phemisation results from playing bottom-up against top-down processing in perception and everyday categorization. Top-down processing is granted pronounced dominance because the reframing is constrained and guided by contextual coherence and value investment sneaks its way into the ad hoc conceptualization. Sharing Zawada's opinion [2006: 250] that "[t]he conceptual structures and processes that underlie linguistic creativity are the essence of linguistic creativity", we resort to reviewing X-phemistic creativity as engaging the manipulation of stereotypical frames associated with primary lexicalizations.

\subsection{Reframing and stereotype modification in recruitment $X$-phemisms}

As Halford and Wilson [2002: 153] contend, "[c]reativity may be defined as the production of effective novelty through the operation of our mental processes." Effective novelty employs the modification of communally shared standrad beliefs and opinion, or stereotypes by designing or recruiting new presentational modes or establishing new lexical concepts ${ }^{11}$ for familiar lexical items (which is the linguistic mechanism for recruitment metaphors). The principle is operative in metaphor as a type of non-literal language as Crespo Fernández [2008: 102] emphasizes:

This constitutes a basic tenet in the Interactive Theory developed by Black (1962 and 1979), which sees metaphor as an intellectual operation with a cognitive import in which the creative response from the receiver allows for a redefinition of the frame, in Black's terminology (or source domain in CMT), as a result of the system of associated commonplaces (i.e. standard beliefs and opinions shared by the members of a community) spontaneously evoked by the focus (or target domain). [Emphasis in bold added].

The creative response from the receiver involves a process of an ad hoc concept creation which taps into standardly held communal beliefs and opinions, i.e. comprehension violates stereotypical conceptualizations ("lexical concepts") and alters valuations. The spontaneous evocation of such a response points out to the fact that the lexical item might be recruited purely by chance without resorting to back stage conceptual metaphors and result in the creation of a new lexical concept with marked X-phemistic properties. An established "lexical concept" provides a stereotypical framing of conceptual content, which X-phemisms take it upon themselves to shake off the established framing associated with the traditional lexical concept and trigger an alternative framing in which the conceptual content associated with a lexical concept is

\footnotetext{
11 As Evans [2007], [2009] insists lexical concepts are "semantic units conventionally associated with linguistic forms" and are an essential part of a user's mental grammar [Evans 2007: 11]. They are relativised with respect to conceptual knowledge structures (cognitive models). Besides its "encoded content" each lexical concept evokes the execution of well-entrenched mental routines of accessing external knowledge structures with different degree of entrenchment, which constitutes the lexical concept's unique profile. In situated use the lexical concept acquires contextually induced informational characterization.
} 
rearranged so as to fit the contextual requirements for salient coherence of attribute assemblage associated with a new lexical concept matched to the familiar lexical item. The result of a lexical concept used as a recruitment X-phemisms is a new attitudinally specified semanticism. X-phemisation surfaces as one of the ways in which "lexical concepts interface with non-linguistic knowledge" [Evans 2010: 604]. These interface processes are achieved through lexical metaphors, which might be derived from conceptual metaphors but do not necessarily do so.

A case in point is the most recent euphemistic dysphemism coined by the Bulgarian media дантели n., f., pl. [dantela n., f., sg., tracery, lace]. "Euphemistic dysphemisms and dysphemistic euphemisms have locutions which are at odds with their illocutionary point" [Allan and Burridge 2005: 15]. In the novel euphemistic dysphemism the lexical item and its stereotypical lexical context evoke pleasant associations about something beautiful and artful. The illocutionary force of the new lexical concept associated with the ad hoc concept has a strongly negative judgmental value. This new semanticism with euphemistic dysphemistic properties дантела can hardly be associated with a well established conceptual metaphor. The general frame associated with the lexical item's nominal profiling is embroidery, the delicate, beautiful product of knitting, etc. The innocuous word acquired strong dysphemistic properties in describing a similarly innocent concept - speaking/verbally expressing a position taken on an issue. The word was used by a number of broadsheet and tabloid newspapers in relation to the positions taken by the Bulgarian Prime Minister in relation to the developments in Libya. The Prime Minister publicly announced in a matter of hours two highly opposing views, which was interpreted as a significant gaff on the part of Bulgaria's Prime Minister. He explained his change of opinion with the "modes (fashions) of talking in Brussels". First in a TV interview he labeled the military operation in Libya a "euphoric adventure triggered by oil money", later the same day he defined the operation as "legitimate, necessary, and right". Asked about the motives behind this dramatic change, he said that his "evaluation of political events is dependent on fashions of speaking in Bruslles". The media were quick to accuse the Prime Minister of confusing politics with fashion catwalks and dubbed his behaviour "дантели". Thus the lexical concept which names a beautiful piece of handiwork became a euphemistic dysphemism for speaking out of tune, without considering the consequences of one's words. Now the word is used to name a person's confused behavior (including verbal) based on the wrong assumptions. Lace production is a housewife's pastime and irresponsible political behavior is framed as a pastime. The dysphemistic properties arise exclusively in the juxtapositioning of the frames of lace production and irresponsible public behavior with political consequences. This novel (novel both in terms of the temporal trajectory of semiosis ${ }^{12}$ and in terms of conceptual creativity) euphemistic dysphemism quickly became very popular as the participants in the communicative act in which it was created were the

\footnotetext{
12 "Meaning-making activity is a trajectory-in-time... It [meaning] cannot be reduced to the semiotic forms that are co-deployed in a given meaning-making activity or their physical-material substrate. Nor is it the object text that may result from this activity. Rather, the locus of meaning is the trajectory. It is useful to consider meaning-making activity as a semiogenetic trajectory that reaches back in time as well as forwards into the future. The relevant viewpoint here is that of the selves who jointly engage in such activities and the perspectives that they implicate" [Thibault 2004: 3- 4].
} 
media and the general public. Its associative complex involves the veiling of one's acts by words, where the veil is so thin that it cannot cover the gaff. It might have distant resonance with the implications of the conduit metaphor (Reddy [1979]), but direct mappings between the source domain of embroidery and the target domain of explaining one's swinging opinions with verbal modes of one's superiors are hard to draw and it is highly unlikely for the majority of people to engage in such convoluted comprehension strategies. It is more likely for дантели as the focus domain for the ad hoc conceptualization to evoke the salient meaning of something light and ephemeral of not exceptionally high significance.

No matter what type of posthoc rationalization process a perceiver of an X-phemism might engage in, in order for a linguistic element to function as an X-phemism it has to have created a tinted emotional reaction or a switch in evaluative judgment in relation to a stereotypically differently valued referent. Through ad hoc dispersal of a stereotyped conceptualization of a referent X-phemisms construe attitudinal rating of social realities in interaction. In being invited to recognize a familiar referent in a new frame, a language user is invited to come up with establishing some kind of analogically motivated structural alignment between the referent and the novel frame it has been associated with. X-phemisation is an instance of category-inclusion assertions (Gibbs [1994]; McGlone [2001]). Novel and semi-lexicalized X-phemisms instantiate attributive-category extension in an analogous manner to the process of novelmetaphor understanding in which according to Glucksberg (quoted after McGlone [2001: 99]) "we rely on our knowledge of the vehicle's stereotypical properties and the attributional dimensions of the topic to construct attributive categories de novo." In X-phemisation the stereotypical attributes of the source and target referents interact by mutually modifying one another and negotiating a novel salience-driven calibration of a coherent conceptualization. X-phemisms lexicalize or in some cases even trigger the establishment of new referential metonymies and metaphors through reframing the denotatum and thus propagating experience-triggered novel stereotyping contexts.

Цедилник п., m., sg. [tsedilnik; "strainer, filter or tightener"] is used to mean "a very hard exam, a make-or-break test". Hardly anything in the concept of straining directly maps onto the examination script. It is possible for a researcher after detailed analysis of the implicational complex associated with the focus frame (the lexical item performing the presentation) to arrive at primary and/or conceptual metaphors such as MENTAL CONTROL IS PHYSICAL CONTROL; DIFFICULT SUBJECTS ARE ADVERSARIES, etc. (with somewhat causal/motivating relation to the X-phemisms) but this is a hardly plausible scenario for how inetractants marshal the understanding of the X-phemism. The lexical item is used to evoke the stereotypical frame (or lexical concept) of a "strainer" and invite the listener to associate both attributively and emotionally a difficult exam and passing through a strainer in a plausible manner by establishing an ad hoc concept. The process of coherent attribute mixing is based both on conceptual metaphor and metonymy: first, the instrument (which is the meaning associated with the wordformation pattern of the dysphemism) is used to subsume the whole event including the results of the activity of straining. At the same time there is metaphoric mapping between the activity of straining and an examination - the students are mapped onto the entity being strained and their experience of exertion, exhaustion and destruction is encoded through the inference chain associated with the state of being strained. The 
ingenuity of the new semanticism lies in its ability to evoke a rich associative complex involving both metaphoric and metonymic reconceptualization strategies which are harnessed by the Graded Salience coherence of the ad hoc concept of being examined experienced as being processed by a strainer.

In other words, with X-phemisms as a special type of non-literal language " $[t]$ he emphasis is thus neither on the characteristics of the target phrase per se nor, generally speaking, just on the discourse characteristics, but rather on the specific factors that appear in the presentational context and the meaning of those factors to the interpreter" [Katz 2005: 204]. The speaker invites the listener to tap beyond the set beliefs and find a contextually plausible interpretation that will reconcile the activated frames in a noncontradictory manner. This leads to X-phemisms influencing the perceptual (point of entry) access to the referent with the result of modulated attitudinal associations being evoked. Katz [2005: 185] emphasizes the strength of representational design as "the interpretation of a given statement is inextricably linked to the manner in which it is presented, and when an explicit context is not available, one is constructed from stored knowledge during the act of comprehension." The socio-cultural ecology of X-phemisms requires that knowledge-based context and on-going discourse-based context interact productively. This is achieved through a salience-driven process of stereotype disintegration and reassemblage of available stored knowledge about the target denotatum and the lexical concept of the source denotatum. The processes of conceptual disintegration (Bache [2005], Hougaard [2005]) and conceptual blending (Fauconnier and Turner [2002]) constitute a single cognitive mechanism. In Bache's view [2005: 1621] "conception can be said perhaps to facilitate perception by means of blending." Xphemisms may be, in our opinion, construed as reinforcing, to borrow Bache's words, "certain types of mental compressions of perception" [ibid.]. X-phemisation collapses first- and third-order blending as defined by Bache. The blending is guided by "optimal innovation" and constrained by salience. The Graded Salience Hypothesis (Giora [1997], [2003]; Huang [2009]) holds it that "meaning is accessed in a hierarchical manner in cognitive processing" [Huang 2009:108]. The salient features are the stereotypical ones that have been entrenched in the conceptualization of a given category or at least in the lexical concept form the source domain. "[C]onsolidated and encoded lexical meanings of a mental entity are always activated in the initial process of comprehension, regardless of the context" [ibid.]. By creating an ad hoc concept interactants readily blend salient properties from both involved denotata. Stretching the Optimal Innovation Hypothesis (Giora 2002) beyond pleasurability and into X-phemisation in general, it is plausible to claim that optimal coherence arising from the interplay between salient features of the co-evoked referents and primed evaluative associations harness the creation of the ad hoc concept, as novelty that allows for the recover ability of the familiar. Optimal innovation operates by creating "novelty that allows for the recoverability of the familiar" [Giora 2002: 11]. Thus salient meanings from both evoked conceptualizations of referents are conjoined and reordered in an ad hoc coherence frame of graded appropriateness which supersedes the stereotypical frames of both denotata.

We hold stereotypes for almost anything around us, because we need to make quick decisions within everyday contexts for standard cognitive tasks. Stereotypes result from abilities to generalize. "The ability to generalize is a central, primitive, hard-wired 
cognitive activity" [Schneider 2004: 8]. Stereotypes are non-informed but stable judgmental values associated with a given concept/category. Schneider [2004: 8] illustrates that this is implied in the meaning of the term itself - "[ $\mathrm{t}$ ]he word 'stereotype' itself comes from the conjunction of two Greek words: stereos, meaning 'solid' and typos, meaning 'the mark of a blow' or more generally 'a model'. Stereotypes thus ought to refer to solid models." Stereotypes are packages of conceptual and attitudinal/evaluative frame-models we use in categorization. They are prototypes with replications of judgmental ratings in the emotional brain. Rigidity and duplication or sameness, which Miller [1982] identifies as central for stereotypes, project these conceptual-emotive models as stable structures used in conceptualization. The content of ster eotypes is varied and it is difficult to spell out a general template for that, but they tend to capture the most salient features of a category and an overall evaluative rating for the category as a hole which is inherited in categorizing individual denonata as members of the respective category. In relying on stored concepts and categorizing as quickly as possible for the majority of everyday cognitive tasks, we heavily rely on such conceptual structures as in such contexts we usually categorize hastily and without much reflection. This is a survival cognitive strategy for achieving efficacy of decisionmaking in everyday situations. Lippmann [1922: 88-89] fathoms that this is so because,

[t]here is economy in this. For the attempt to see all things freshly and in detail, rather than as types and generalities, is exhausting, and among busy affairs practically out of the question.... Instead we notice a trait which marks a well known type, and fill in the rest of the picture by means of the stereotypes we carry about in our heads.

$\mathrm{X}$-phemisation intervenes in such processes by offering a new focus into the perception and conceptualization of the target denotatum and involves interactants in a process of disintegrating their stereotypical perceptions of denotata and triggering off a reframing by guided attention to context-relevant blended reordering in terms of salience. Stereotyping follows a general cognitive and socio-psychological pattern which is directly mirrored by processes of X-phemisation. Stereotypes are kinds of "universal judgments" and accompany the situated categorization of entities and their uncritical appraisal which instead of being contextually triggered, seem to be stable and almost auto matic pieces of background knowledge. X-phemisation recalibrates stereotypes by modifying the hasty attitudinal and judgmental evaluative associations.

As in different types of nonliteral forms it is possible for mixtures of mechanisms and processes, some of them contradictory and others complementary or parallel, to underlie the creation and interpretation of X-phemisms. The above claims hold water when the listener has recognized the X-phemism as such, no matter what the intentional motive of the speaker is. In case an X-phemism falls on deaf ears, its attitudinal validity is canceled and whatever comprehension it triggers the uniquely X-phemistic appraisal value is lost The reframing may be still activated but the linguistic phenomenon will be another type of non-literal language, not an instance of X-phemisation. Recruitment Xphemisms always evoke inflated perception and disturbance in a referential stereotype accompanied by attitudinal value fixation. The active involvement of the listener is crucial in the functioning of X-phemisms because X-phemisation is a paradigm case of 
what Deborah Tannen [1986:106] identifies as 'interactional frames'. She distinguishes between frames as knowledge structures and frames as active sites of negotiating meaning and what is actually going on. In her view knowledge structure schemas are "expectations based on prior experience about objects, events, and settings", "a superordinate definition of what is being done by talk, what activity is being engaged in, HOW a speaker means what she says" [ibid.]. Under this refined classification of schemas and frames, X-phemisms appear as instances of an interactional frame in which a speaker instructs a listener to discard familiar frames associated with a referent and reconceptualize it by employing a different stereotype. "Interactive frames, but not knowledge structure schemas, are always a matter of two logical types: the concrete, particular way of speaking in the interaction, and the abstract set of associations that identifies the culturally significant interactive goal being served by that way of speaking" [ibid.].

Recruitment X-phemisms violate neutral, standard affordances of perceivables and overcome the stereotypical associative complexes that have been captured in a culture in conceptualizing a certain entity in a particular way and standardly relying on a particular lexical concept to provide easier access to it. They are metonymic in essence, because they realize the principle of highlighting a particular referent by activating a contextually salient or overtly presented entity closely associated with the referent in terms of conceptual contiguity (Lakoff and Johnson 1980; Lakoff and Turner 1989). To pay justice to the facts of X-phemisation, we need to admit that both the principles of resemblance (by implicit comparison), i.e. the principle of metaphor and the principle of referential contiguity are both operative in recruitment X-phemisms. Goossens' "metaphtonomy" aptly captures the impossibility to separate the engagement of both principles in X-phemisms. In analyzing the fully lexicalized dysphemism in Bulgarian озъбвам се на някого [оzybvam se na nyakogo, "bare one's teeth at someone", argue severely with someone, to oppose in a nasty manner] is a case in point which can illustrate the difficulty in tracing the ordered activation of metaphor and metonymy in interpreting complex instances of conceptual integration. The metaphor MENTAL ACTIVITIES ARE PHYSICAL ACTIVITIES provides the metaphoric frame, but the baring of teeth is also metonymic in relation to the literal lexical concept associated with the lexical item. This metonymic reading is induced by the BODILY REACTION FOR EMOTION metonymy, which is a special case of the more general EFFECT FOR CAUSE metonymy. The physical activity is typical of aggressive behaviours in dogs, which is interpreted as intimidating and indicating aggression. The impossibility of establishing an ordered sequence for the operation of the conceptual metaphors and metonymies in interpreting the reframing of "agitated arguing" as teeth-baring only comes to indicate that metonymy and metaphor are inextricably intertwined in X-phemisms as a special type of non-literal language.

The construction of ad hoc X-phemistic concepts is driven by constraint satisfaction the constraints relate to coherent blending of the bifurcated referentially anchored perception. The complex process of frame compounding is not as a simple as creating a master list of the features of both denotata, but involves an ordered sequence of disintegration and reintegration of salient features, driven by the the tacit acknowledgment that "[...] the general outlines of framing are understood not by atomistic structural representation of components of frames but by seeing the relationships among an array of particular dimensions of framing" [Tannen 1986: 107]. 
The invited reframing is first constrained by the proffered integration frame and second by the drive for coherent conceptualization into a Gestalt, which imposes the constraints of blending and coordination in a heightened and specifically windowed perception. Recruitment X-phemisms window the perceiver's attention and provide the scaffolding against which the novel conceptualization is accomplished.

Ad hoc conceptualization can only be executed after the referent of a piece of discourse has been established. This, as Barr and Keysar [2005: 28] remind us, depends heavily on a speaker's lexical choices - " $[t]$ he expression that a speaker chooses in referring to some object-from an elaborate, full noun phrase to a simple pronoun - will depend on the degree to which the referent is in the focus of attention in the discourse." Besides this reliance on mutual knowledge for the disambiguation of reference, the choice of recruitment X-phemisms contains subtle instructions ${ }^{13}$ for the particular manner in which the interactant has to focus on/perceive the referent. The attitudinal value triggered by recruitment the X-phemism is of a specifiable kind - either positive or negative (both in terms of affect and in terms of judgment). Thus both fully lexicalized and novel X-phemisms trigger the listener's fine-tuning of referent comprehension/perception as a different window of access is prescribed over and above the purely perceptual affordances in a communicative situation which invites situated cognition.

Situated cognition suggests that humans use situated versions of concepts that have context-specific functions, and do not automatically activate the same, contextindependent conceptual frame in every situation (Yeh and Barsalou [2006]). Reframing will involve at least rearrangement in terms of salience in the complex configuration of the ingredients which constitute the conceptual frame of the non-stereotypical ad hoc concept formation.

An example from the implicit attitudinal lexicon in Bulgarian used for the expression of approval is гадже убиещ/mрепач n., n., sg. [gadzhe trepach, "a killer/beater girlfriend"], which functions as a dysphemistic euphemism with the meaning of "an extremely attractive young girl". From the instructional perspective of language on hearing a girl described as a killer the listener's mind-set is invited to focus its attention on particular fetuares marked as salient by the speaker in choosing this particular lexical concept. A plausible, but highly unlikely, interpretative hypothesis might be to conceive of the girlfriend as being a serial killer (in analogy with the "serial/black widow" stereotype) which would hinge on the literal salient meaning of the lexcical concept stereotypically associated with the lexical item убиеи. However, the dysphemistic euphemism is unfailingly understood as expressing a highly positive attitudinal stance on the part of an aloof speaker projected as a victim to the power of attractivenss of the situational referent. This interpretation reveals its conceptual relatedness to a whole series of conceptual metaphors PSYCHOLOGICAL FORCES ARE PHYSICAL FORCES; EMOTIONS ARE FORCES; DESIRES ARE FORCES BETWEEN THE DESIRED AND THE DESIRER, SEXUALITY IS AN OFFENSIVE WEAPON, which as ingrained knowledge structures facilitate the contextually coherent construction of the ad hoc concept of a beauty being perceived in a particular way.

\footnotetext{
13 "Instructions" is meant here as shorthand for Harder's model of meaning as input or the instructioinal perspective on linguistic interaction, according to which "words are designed to prod, or prompt, the addressee to carry out interpretative activities of a specifiable kind" [Harder 2009: 15; emphasis added].
} 


\section{Metaphtonymy in idiomatic X-phemisms}

As back stage stable knowledge structures conceptual metaphors and metonymies aide and sometimes even provoke the functioning of X-phemisms as associative primes. They might underlie both monolexemic and idiomatic X-phemism, even though the latter differ in terms of their presentational design. Monolexemic X-phemisms differ from idiomatic ones in terms of conceptual only vs. conceptual and linguistic collocation. The distinction between collocation at the conceptual level only and at the lexical level can be illustrated through the difference between гъз глава затрива [gaz glava zatriva, "the ass kills the head", eat someone out of house and home] and насоля v, tr./intr., perf., [nasolya "season with salt", scold severely]. In the first instance the lexical item is in the form of a phrasal unit with explicit collocational preferences encoded, while the second is in the form of a single word and all semantic orchestration belongs to "backstage cognition" (Fauconnier [1997]). With the first the presentation design is more palpable and "graphically" presented spelling out a whole scenario, while the second one presents only a point of entry in a compounded ad hoc-concept. Both are fully lexicalized and should not display processing differences. However, details in representation matter, so that idiomatic X-phemisms are more likely to be associated with a uniform appraisal value across contexts, while monolexemic ones are more likely to freely fluctuate along the rhetoric dimension from euphemisms to dysphemisms in the euphemistic treadmill (Chamizo Domínguez 2005; Pinker 2008).

The fixed appraisal value is culturally tailored, even if the same metaphtonymic complexes underlie the X-phemistic expressions in two languages. The contrasts between гъз глава затрива and eat someone out of house and home illustrate the cultural specificity in exploiting the same set of conceptual metaphors. The two expressions differ in terms of their dysphemistic strength, i.e. the intensity of the negative associations. They also differ in degree of figurativity or idiomaticity. The English expression is mildly figurative, while the Bulgarian one is more conspicuously non-literal, which results from the differences in their presentational mode. Even if we assume that in both languages the motivating or source domain is that of FOOD/EATING, in English the mapping is significantly more direct, while in Bulgarian a complex metaphtonymic series is involved. Presentationally, eat is evaluatively neutral, and the domain is evoked by an orthophemistic expression, while 233 is strongly dysphemistic (considered in its bodily meaning a taboo) and only metaphtonymically associates with the FOOD (or to be more precise the consumption of it) domain. The dysphemistic rating of the two expressions is correspondingly different - the English one is mildly dysphemistic - the dysphemistic associations relate to the activated scenario of living on the streets, while in Bulgarian the expression is palpably dysphemistic as it utilizes a taboo lexical item - 2ъ3. Recognizing a shared target conceptual content ("being gluttonous has dire consequences") helps distinguish the role of dysphemistic creativity in the two languages.

With conceptual metaphors exploited in X-phemisation it is either the nature of the source domain (in relation to the target denotatum) or the incongruity of the activated stereotypical frames from the source and target domains that creates the X-phemistic 
effect. Extremely important is the actual wording or the specific lexical concepts involved as each lexical concept provides differential access to the domain. The underlying conceptual metaphoric complex involves holistic mapping between the two domains but lexical concepts can tap different areas and highlight specific portions of the domains. Both to force-feed (as in "being force-fed information is a habit one can break" $O E D$ ) and savour (as in "We savour at our leisure the delicate satire which we were too excited to appreciate duly" OED) rely on the conceptual metaphor IDEAS ARE FOOD, but only the first has heightened dysphemistic overtones. The lexical concepts chosen to probe into the metaphoric complex, with their specific perceptual associations and the nature of physicality implied in them, predispose towards opposingly marked Xphemistic perceptions.

What is more besides specific lexical concepts, certain domains when used as source domains in conceptual metaphor have higher proclivity for producing X-phemistic effects, while others will produce figurative encoding of a target domain, but will not readily yield X-phemisms. The FOOD domain and the SEEING domain are both used as source experiential matrices for conceptualizing "understanding / comprehension" and they have different proclivity to X-phemistic implications when used in this line of metaphoric conceptualization. The former has an intrinsic propensity to be exploited through metonymic shifts with marked dysphemistic effects as it is the processing of food that is experientially associated with potentially tabooed or displeasing human experiences. The detection of the respective conceptual metaphor is not sufficient for evoking a definite affective stance. The stretch from the experiential complex which is chosen for representation with its contiguous lexical concepts modifies the ad hoc blended conceptualization in a way which moulds the affective stance. The evocation of entrenched conceptual metaphors is not sufficient for engendering specific X-phemistic effects as becomes obvious from contrasting the utilization of the same underlying conceptual metaphor in two cultures. The nature of the literal meaning of eat s.o. out of house and home guarantees its evaluative innocence in comparison to its Bulgarian translation equivalent гъз глава затрива. In the English encoding a rather central and general lexical concept from the FOOD domain is utilized in the metaphoric transfer, while in Bulgarian a peripheral and marginal constituent of the frame is recruited which constitutes part of the "eating domain" only via conceptual metonymy. The presented part of the experiential complex in Bulgarian is associated with the end phase of processing food (digestion) and metonymically with the bodily organ involved in this phase of expelling unnecessary food from the body. The conceptual content (or if terminological stretching is made use of, the referent) of both expressions is roughly the same but their dysphemistic properties and their presentational modes (with the corresponding experiential complexes) differ resulting in different affectual values. In the comprehension process probably the whole domain will be accessed but the taste in the mouth (to analytically piggyback on the conceptual metaphor IDEAS ARE FOOD) is asso ciated with the first anchor into the domain - the lexical items chosen chosen with their stereotypical lexical concepts and all their literal/non-literal ambiguities implied. The connotations associated with the literal meaning of the source domain used to refer to the target concept play a significant role in determining the specific X-phemistic charge of the resultant conceptualization based on the lexical concept from the source 
domain. Ultimately socio-cognitive and cultural variables in the context will determine the actual X-phemistic effect of the particular utilization of a conceptual metaphor.

\section{Dysphemistic verbs}

The dependency of X-phemistic effects on the presentational mode chosen (i.e. the specific lexical concepts recruited from a source/vehicle domain) is observed not only in idiomatic X-phemisms derivable from established conceptual metaphors but also in dysphemistic verbs. Bolinger [1980: 80] believes that verbs are the least likely lexemes to have X-phemistic effects, "[o]f the three major classes of words, verbs seem least hospitable to bias. This is probably due to the transitory nature of what they name." Recognizing the contextually specific, online ad hoc concept construction as the conceptual mechanisms behind X-phemisation frees the classes of words from ranking in terms of conceptual stability that could maintain the attachment of approval or disapproval. The recruited verbal lexeme may have inherent disapproval associations or such may be created in the blending of the frames. The act of choosing to "display" the intended meaning via the stereotyped frame of a given lexical item triggers an attentional switch and attitudinal revaluation. This process of reframing is guided by the "naturalist hypothesis", which as defined by Allan and Burridge [1988: 7] and [1991: 22] has it that "the form of an expression somehow communicates the essential nature of whatever it denotes." Form does not relate here to the expression plane (i.e. it is not sound symbolism that is implied). Form is intended to capture the uniqueness of the cognitive effects achieved by the use of a particular lexical item which carries with it an instruction for a particular conceptual access to a referent ${ }^{14}$. As will be illustrated below, verbs can be extremely powerful dysphemisms in relation to or thophemisms (be it of tabo o activities or of neuter activities), because "[ $\mathrm{t}$ ] he key to understanding the nature of linguistic competence and its acquisition [...] lies in the dialectical relationship between bodily dispositions and activities on the one hand, and sociocultural practices on the other" [Zlatev 1997: 1-2], (emphasis added).

"Choosing" or "selecting" is not in itself a taboo concept, nor are most of the words we use to name such activities, but заплюя v., tr, perf., заплювам си v., tr, imperf., [zaplyuya, zaplyuvam si "spit on, mark so mething as one's possession by spitting on it", choose, pick out] present the activity of choosing as a nasty, even physically repulsive behavior. The strongly dysphemistic properties of the verbs arise from the bodily dispositions and activities and the sociocultural practices associated with the anchoring/profiling stereotypical frame of the domain associated with the actual lexical item used.

Dysphemistic properties may arise out of the salient properties of the stereotypical concept (including the lexical one) associated with the intended (target) denotatum as is the case with the Bulgarian dysphemistic прецаквам v., tr, imperf., [pretsakvam, "crosstrump", spoil s.o.'s plans]. The lexical item belongs to the domain of playing cards. It relates to the possession and playing of trumps. The creativity of the dysphemism is at

\footnotetext{
14 As one of Domínguez's theses states [2005: 10] an X-phemism "cannot be replaced by any other word and still achieve the same cognitive effects."
} 
sub-lexical, morphemic level. The intricate X-phemistic play results from "interlexicality" (Munat [2010]) and substitution of a prefix. In the context of playing cards the idea of playing a stronger trump than the one of one's opponent is lexicalized in - надцаквам v., tr, imperf, [nadtsakvam, "overtrump"] and this is an attitudinally neutral or even positively marked lexical item. The playful substitution of the prefix results in an attitudinal switch which leads to the highly dysphemistic properties of прецакам, which is not used in the neutral context of playing cards due to the bidirectional interaction between source and target. The most cognitively effective (or at least most effortsaving) interpretative strategy is to metaphtonymically associate spoiling s.o.'s plans with having more powerful trumps and thus prevent the opponent's winning, i.e. the realization of someone's plans. The negative attitudinal result stems form the stereotypical concept of "purposefully spoiling s.o.'s plans".

"Contamination" or the specific evaluative colouring of an X-phemism can arise from the topic denotatum, from the vehicle denotatum or from the blending of the contextually salient features of both (no matter if it is a figurative expression or a monolexemic substitute to the exclusion of phonetically-based innovations). As "expressions are not nasty by themselves" [Allan and Burridge 1988: 7], it is natural to conclude that dysphemistic effects can only stem from culturally informed conceptualizations of one of the denotata or the ad hoc concept, i.e. the dysphemistic effect is derived from choosing a particular framing perspective which achieves an attention switch that leads to modifications in salient features ordering. Put simply, Xphemisms function as instructions for perception, i.e. they invite the listener to perceive the referent as construed in a particular frame within the interpretative practices of a given culture. Singer [1998: 5] defines culture as

a pattern of learned, group-related perceptions - including both verbal and nonverbal language, attitudes, values, belief systems, disbelief systems and behaviours that is accepted and expected by an identity group. [Emphasis added].

As one of Chamizo Domínguez's theses on X-phemisms proclaims, X-phemisms have special cognitive and social effects which make them distinct from metaphor (with which they otherwise share a number of constitutive features] [Chamizo Domínguez 2005: 13]. Central among the special effects of X-phemisms is their "aptness" of presentation function [Kress 2010: 55], in keeping with which the chosen linguistic resource is perceived as the most apt one to realize the intended meaning in the specific context. They acquire their attitudinal power by heavily exploiting the (re)presentational ${ }^{15}$ dimension of language.

Crespo Fernández [2008: 96] defines dysphemism as "the process whereby the most pejorative traits of the taboo are highlighted with an offensive aim to the addressee or to the concept itself." This restricts the scope of dysphemisms only to cases in which the

15 "[T] he representational implement of language ranks among the indirect means of representing, it is a medial implement in which certain intermediaries play a part as ordering factor " [Bühler 2011: 171; emphasis in the original]. By the (re)presentational side of communication is understood the ability of lexical items to invite and evoke different 'viewings' of a referent. In the parlance of LCCM theory (Evans [2009]) the representational dimension relates to the possibility of one and the same cognitive model to be accessed by different lexical concepts with different properties and routes of access activated. 
dysphemistic properties are derived from the traits of the target denotatum or when dysphemisation arises from conceptual interdiction. "Highlighting" is only possible if the properties are already present in the conceptualization of the denotatum. Often dysphemisms relate to innocuous or affect-neutral denotata and the process of dysphemisation is not one of "highlighting" the properties of the referent. Rather new properties are ascribed to the denotatum by its being accessed through a different lexical concept. The lexical concept used to name the vehicle (source) functions as a conceptualizing anchor (or beamer) which actively participates in the ad hoc conceptualization which is salience-driven and triggers property reordering in keeping with a new frame provided by the executed lexical concept. This is typically achieved by associating conceptually the topic referent with the stereotypical frame of another one (the vehicle), thus blending the stereotypical conceptualization of the topic (target) denotatum with the stereotypical conceptualization of the vehicle referent.

Dysphemisation (i.e. downgrading or offending the referent/interactant) is not infrequent with orthophemistic, "innocent" or evaluatively uncoloured denotata. The verbal lexicon in Bulgarian in the semantic field of "working" is replete with dysphemistic expressions naming working. The denotata are neutral, hardly anyone (to the exclusion of sleuths) will hold negative associations with the human activity of working. The dysphemistic colloquial verbs used invite an obvious reframing of the activity of working (e.g. all the verbs below have the general meaning to overwork, to work one's fingers to the bone: бича [bicha, "to saw trees", work too much], бъхтя (се) [bahtya (se), "to push around, to beat", work long hours, work strenuously]; блъскам (ce) [blaskam (se), "to push against", work hard, overwork]; счпnвам се [schupvam se, "break", work hard]; изгърбвам се [izgarbvam se, "bend over, stoop, get a hunchback", work toо тисh]; скъсвам се [skasvam se, "tear oneself", work toо тисh], скъсвам си гъза [skasvam si gaza, "tear one's ass", work too тисh], сбръчквам се, сбръчкам се [sbrachkvam se, "to wrinkle, to get wrinkled", overwork], трепя се, претрепвам се [trepya se, pretrepvam se, "kill oneself, do away with oneself", overwork]). When instead of using an orthophemistic expression a speaker resorts to one of these verbs, working is dysphemistically presented; framed as physical effort, adverse physical effects on the body or suffering to the point of death. The same dysphemistic effect is observed in the use of diminutives for the names of the professions. Instead of conveying dignity to a (menial) profession or job (as is one of the functions of euphemisms according to Domínguez [2005]), diminutives convey unsatisfactory or poor qualities of the person perfoming the job (see part 6). In such instances (creating dysphemisms for orthophemistic denotata), dysphemisation becomes a powerful appraisal resource in language, since the dysphemistic associations directly reveal the speaker's evaluative stance as these are not inherent in the stereotypes for the respective denotata. Admittedly, certain experiential domains are predisposed towards providing reframing conceptualizations with the effect of verbal plummeting - "breaking"/destruction", "dirt", etc. and these are the ones most frequently utilized in creating dysphemisms for orthophemistic referents. This understanding is fully in keeping with the definition provided by Allan and Burridge [1991] according to which a dysphemism is "an expression with connotations that are offensive either about the denotatum or to the audience, or both, and it is substituted for a neutral or euphemistic expression for just that reason" [Allan and Burridge 1991: 26]. So offensive connotations arise when a 
particular expression is used instead of a neutral or euphemistic expression naming the same denotatum - e.g. orthophemism работя много (rabotya mnogo, "work hard") represented in discourse as стопяват ми се лагерите [stopyavat mi se lagerite, "my bearings/gudgeons melt", work very hard]. The first expression is neutral and states the situation in which the speaker works too much with no indication as to the attitude of the speaker to this fact, via the second expression the concept of working hard and a lot is framed in a dysphemistic manner where the working person is construed as a machine which has been overused, i.e. as a fragile, easily breakable object. The dysphemistic effect is linked with conceptualizing working as an adverse, destructive force and not as an ordinary fact of life.

Of course dysphemisms can be used to reinforce or intensify socially stigmatized concepts/referents, as is the case in the following dysphemism разкоствам v., tr,imperf, разкостя v., tr, perf., [razkostvam, razkostya "take the bones out of, debone", to strip something of its basic parts, to dismantle or cannibalize]. The strongly dysphemistic verb encodes the vandalization of objects (predominantly used for stolen property: cars, TV sets, PCs, etc. sold in parts) by evoking the conceptual metaphor CHANGE IS LOSING. The literal meaning of the verb relates to the deboning of foods and is evaluatively neutral as common sense and cultural practices of cooking indicate that deboning is a necessary change/procedure for accomplishing a desirable goal (even though the procedure involves the manipulation of dead animal bodies). In its dysphemistc meaning, the verb reframes the dismantling of mechanical entities as depriving an object of its essential parts. The dysphemistc effects arise out of compounding the properties of a socioculturally desirable activity and of a socio-culturally abhorred activity. The lexicalized local metaphor PARTS ARE BONES frames the compounding of features and capitalizes on the inherent culturally motivated valuation of the referent for achieving the highly dysphemistic effect.

\section{Morphopragmatics and X-phemisation}

It turns out that size matters. Ruiz de Mendoza [1996] defines Spanish diminutives as attitudinal term operators that codify axiological relatedness between speaker and referent. In a like manner, Bulgarian diminutives constitute a flexible resource for the whole attitudinal range: expressing affect, judgment and appreciation, inseparably intertwined in a single suffixal blend. These functions render diminutives in Bulgarian agents of intricate X-phemistic functions without relying on figurativity in reframing. Yet, they do involve elaborate patterns of reframing. The linguistic process of diminution is a central appraisal resource utilizing reframing and heavily relying on metonymic projections. Diminutive suffixes in Bulgarian function as reframing prompts in which the rich association complex attached to them has to be contextually gauged in understanding the specific socio-cognitive motivation in using a diminutive word. After all, as Wierzbicka [1992: 150] claims, "[w]ords are a society's most basic cultural artifacts, and they provide the best key to a culture's values and assumptions - on condition that they are properly understood."

Bulgarian is among the languages with richly developed system of both denotative and connotative diminutives. Even though denotative diminutives also have an 
evaluative bias, it is connotative diminutives that are mostly deployed as powerful Xphemisms. With in the Bulgarian linguistic tradition Zidarova [2005, 2008] claims that nominal diminution in Bulgarian is generally associated with predominantly denotative semantic contribution on the part of diminutive affixes, while in the derivative diminutives from bases that belong to other lexical classes the emotive-evaluative predominates due to the specific nature of their denotative character [Zidarova 2008: 1]. The distinction between denotative and cannotative diminutives can be summarized in the opposition between using diminutives to designate one of the core denotative components of dimunition - "smallness", whereas connotative ones are used with a variety of semantic effects. The diminutive suffix -чe (che) in itself is usually exploited for denotative diminution associated with actual smallness of denotata or with and is usually associated with positive connotations: краче n., n., sg., [krache, "leg-DIM"], столче n., n., sg., [stolche, "chair-DIM"], палче n., n., sg., [palche, "thumb-DIM"], etc. Connotative diminutives on the other hand do not depend on the denotative feature "smallness". Their predominant function is the projection of an evaluative stance. X-phemisation within diminution can be detected only when there is a switch in markedness, i.e. when the social sensitivities of interactants predispose them towards the use of diminutives likely to evoke or express positive attitudes to something that need not be positively marked in the emotional brain (Тя е истинска кукличка. [Tya e istinska kuklichka. She is a real doll-DIM]) or the reverse, a denotatum not necessarily negatively marked is framed or named by linguistic resources evoking or expressing negative attitudes - e.g. един животец n., m., sg., [edin zhivotes, "one life-DIM"]. While Тя е истинска кукличка is $\mathrm{X}$-phemistically ambiguous, i.e. it might be used euphemistically or dysphemistically, the noun phrase един животец is dysphemistic as it designates a way of life devoid of the basic features of living, not worthy of the fully-fledged lexical concept life. Even if we assume that the denotative (literal) feature "small" is activated as a default component of the diminutive noun, "lack of" or "insufficiency" are by implication also evoked. Nominal diminutives from positive abstract bases e.g. щастийще n., n., sg., [shtastiytse, "happiness-DIM"] tend to be dysphemistic as they imply reduction in the positive features associated with the concept (even in cases when the base does not name a potentially gradable concept). Such dysphemisms express negative attitudes and more importantly ascribe negative features to the denotatum. Щастийце implies that the feeling of happiness is so miserable that it cannot be named with the neutral, nondiminutive lexeme щастиe, or by ironic implication it is used to name an actual experience of unhappiness. Животец is restricted to the first dysphemistic interpretation only, in which the way of living is of such low quality that it can't possibly be worthy of being named by the non-diminutive lexeme. In кукличка n.,f., sg., [kuklichka, "doll-DIM"] the referential metaphor ("doll" used to describe the behavior of a human), operationally modified by a diminutive, can be read euphemistically to indicate endearment and attachement in cases in which the speaker describes a little girl but it would be ironically dysphemistic in cases in which the diminutive is used in a context in which the referent cannot genuinely be associated with the denotative feature "small".

When used with nouns denoting professional occupations diminutives also strongly deviate from the positive evaluative stance supposedly ${ }^{16}$ associated with them and

16 Reference is made here to the proverbial positive evaluation associated with diminutives, captured in 
result in dysphemisms. A possible explanation for the dysphemistic function of diminutives with professions stems from the impossibility to associate "smallness" as a default feature with the denotatum. The names of professions themselves can have positive or negative connotations stemming from the nature of the denoted profession, but attitudes associated with the denotatum are not necessarily directly reflected in the linguistic resources (orthophemisms). When using diminutives with names of professions the semantic effect is the predication of inadequate or insufficient professional qualities of the specific referent. When describing someone as докторче $\mathrm{n}$., n., sg., [doktorche, "doctor-DIM"], писателчe n., n., sg., [pisatelche, "writer-DIM"], журналистче n., n., sg., [zhurnalistche, "journalist-DIM"], даскалче n., n., sg., [daskalche, "teacher-DIM"], nрофесорче n., n., sg., [profesorche, "professor-DIM"], etc. a speaker does not mean that someone of young age is practicing the profession. Rather the dysphemistic meaning is to express disregard, low esteem or a slighting attitude to the practitioner of the profession. This interpretation is harmonious with Dressler and Merlini Barbaresi's [1994:144ff.] formulation of the basic morphopragmatic meaning of diminutives:

The general morphopragmatic meaning of diminutives is the feature [non-serious], which relates to the morphosemantic feature [non- important], which is related via metaphor to the morphosemantic denotation [small].

In the lexis of professions in Bulgarian, diminutives preserve the feature [nonimportant] but it is exploited for the expression of lack of or low level of professionalism on the part of the referent, not the prototypical positive emotive-evaluative associations "playfulness, meiosis, love, sympathy and empathy", which Dressler and Merlini Barbaresi [ibid.] associate with diminutives via metaphoric extension from the central denotative features thereof. Profession diminutives are used to express the speaker's negative attitude to the professional conduct or achievements of the referent by direct application of the feature [non-serious] to the referent. It bears the implication that the referent is either incapable to practice their profession at the required standards or the performance is exceptionally poor.

Adjectival diminutives derived in the area of subjective valuations of taste from negative bases have marked euphemistic effects especially in answering a host's questions concerning the food served: киселичък adj, n., sg., [kiselichak, "sour-DIM"], горчивичък adj, n, sg., [gorchivichak, "bitter-DIM"], соленичък adj, n., sg, [solenichak, "saltyDIM"]. The guest is experiencing discomfort but politeness requirements invite them to approach the issue in a delicate manner by belittling the unpleasantness of the experience.

In non-committal expression of opinion or appreciation of objects diminutives function as indicators of lack of specific interest. These are derived from positive lexical bases - интересничък аdj, n., sg., [interesnichak, "interesting-DIM"], хубавичък adj, n., sg., [hubavichak "pretty-DIM”], приятничък adj, n., sg., [priyatnichak, “pleasant-DIM'”]. The

Wierzbicka's contention that "The central place of warmth, of affection, in Slavic as well as in Mediterranean cultures, is reflected, among other things, in the rich system of expressive derivation, and in particular in the highly developed system of diminutives." [Wierzbicka 1991: 50] 
communicative function of such diminutives is not to indicate objective lowering of the property possessed by an entity, but to indicate disinterested attitude on the part of the speaker. Typically they are used in confirming an evaluation offered by the interlocutor. The adjectives which tolerate diminution of this type are neutral or occupy the pivotal region as defined by Cruse [1986: 205] or ones which name the possession of the property to a neutral degree. Adjectives expressing a point of satiation of the property in either the negative or positive poles do not permit diminution. *завладяващичък adj, n., sg., [zavladyavashtichak, “captivating-DIM"]; *опияняващичък adj, n., sg., [opiyanyavashichak, metaphoric extension of intoxicating meaning "extremely pleasant and intriguing-DIM"].

Positive adjectives with diminutive affixes usually function as boosters - they reinforce the positive features of the denotatum via the connotations of positive evaluation traditionally associated with diminutive affixes. This results from the prototypical concept 'small/child' which many among whom Wierzbicka (1984) and Jurafsky (1996) recognize as central for diminutive affixes. However, in a carnivalesque manner such positive adjectives can acquire ironic negative marking and become dysphemistic, when the speaker purposefully avoids acknowledging their negative attitude to the denotatum. By utilizing diminution the speaker inadvertently achieves the effect of subtle awareness in the interactants of a strong negative attitude which might be perceived as insulting or merely humorously deprecating. Хубавичък adj, n., sg., [hubavichak, "pretty-DIM"] - can mean extremely nice or ugly. Such dysphemistic euphemistic diminutives (which they may become only when not used in communication with children) friends usually imply dismissive deprecation or ironically feigned 'approval'. As has become obvious, dimunition in Bulgarian has a reserved place in the appraisal system executed via X-phemisation. We are far away from having understo od the inticacies of X-phemistic dimunition in terms of its complex rhetoric. As Kryk-Kastovsky [2000: 173] aptly summarizes,

[D]iminution is a much more complex and multifarious process than has been believed so far. Languages whose word formation rules allow an almost unlimited derivation of diminutives are characterised by a high degree of semantic and pragmatic complexity.

Amidst this complexity Sáenz [1999] elaborates two central metonymic transfers which associate emotional attitudes with conceptualizations of the denotata of diminutives and indicate their rhetoric potential for encoding contradictory stance positions: a) smallness via its conceptually contiguous manageability when ascribed to entities renders them more likeable; b) the possibility to ignore small entities due to their perceived innocuousness renders them unpleasant. Along this cline between adorable and repulsive, dimunition challenges the creativity of humans as rhetors by offering ample resources for carefully grading attitudinal stances in every instance of language-mediated interaction. 


\section{Concluding remarks}

X-phemisms function as communication adaptation strategies which stem from the conscious discursive positioning of the speaker in relation to interactants and entities spoken about. They are not simply cross-varietal synonyms - they always add the dimension of affect and thus constitute neo-semanticisms, not simply synonyms with differential sociological or stylistic effect - they encode the affect dimension and it becomes part of their multidimensional semantic constitution in the process of subsequent lexicalization. They usually involve low transparency as they display morphotactic or morphosemantic complexity and thus require active involvement on the part of both interactants. Most are figurative in the sense defined by Kövecses ${ }^{17}$ [2008: 380] - they are not direct names, but are rather derived metaphtonymically. As an active, dynamic, contextually modeled multidimensional process X-phemisation can be approached from a variety of perspectives, not all of which would be readily identified as strictly linguistic. In the present paper the focus within the multifaceted Xphemisation process was on the involved re-conceptualization of the denotata with an implied evaluative recalibration which renders the overall result X-phemistic no matter if X-phemisation results from purposeful communicative behavior or is an inadvertent and accompanying side-effect of a linguistic/social gaffe.

Three types of language independent factors play significant roles in motivating and guiding creativity in X-phemisation processes - ecological, experiential and cognitive motivation. It is difficult to draw an analytically significant distinction between experiential and cognitive motivation in X-phemisation as the two are closely related, so cognitive was used as a blanket term, with no detailed discrimination being specified between cognitive and experiential motivation for X-phemisms. The ecological motivation behind X-phemisms is captured in their unique socio-cultural functions within the appraisal system of languages and their stance-taking properties. Being inferentially overpotent, X-phemisms invite a complex process of alignment, which involves creativity both on the side of the speaker and on the side of the hearer. From the point of view of the speaker, the choice of the expression provides "predictive control", as elaborated by Schneider [2004: 64]:

$[w]$ e group things into categories because we expect that the things within a given category will be similar in some ways and different in others from things alien to the category. This gives us predictive control over the environment, a leg up in deciding on appropriate behavior.

For the hearer, this is an invitation to go beyond the stereotypical framing of the denotatum and engage in situationally tailored reframing. In this respect, as indisputable appraisal effect agents X-phemisms provide a rich area for further research in the complexity of appraisal as permeating the lexical units, not only the systems of the lexicogrammar.

\footnotetext{
17 In describing the nature of emotional language Kövecses [2008: 380] defines it as "highly figurative; that is, it is dominated by metaphorical and metonymic expressions." For him figurativity is measured by the degree of metaphtonymisation.
} 
X-phemisation is in its greater part recruited for the encoding of implicit attitude, i.e. utterances in which attitudinal assessment cannot be directly and overtly questioned and this is what makes X-phemisms such powerful appraisal resources. X-phemisms are vents for the conceptual creativity and the socio-emotive sensitivities of humans. The significance of findings associated with their study far outweighs the complexities in their research.

\section{Bibliography}

AGHA Asif, "Ideologies and practices of identity. Comment on Bucholz": http://language-culture.binghamton.edu/reviews/symposium7/agha.html n.d.

AllaN Keith and Kate, Forbidden Words: Taboo and the Censoring of Language, Cambridge, BURRIDGE Cambridge University Press, 2006.

ALLAN Keith and BuRRIDGE Kate, "Raising Gooseflesh: 'Dirty' Words and Language Change" in Latrobe Vol. 5, 1992, at

http://arrow.latrobe.edu.au:8080/vital/access/manager/Repository/latrobe:330 39? exact=title $\% 3 \mathrm{~A} \% 22 \mathrm{La}+$ Trobe+working+papers +in+linguistics.+Volume $+5+\% 2$ 81992\%29\%22 (accessed April 2011)

Allan Keith and BURRIDGE Kate, "Euphemism, Dysphemism and Cross-varietal synonymy", 1988, at

http://arrow.latrobe.edu.au:8080/vital/access/manager/Repository/latrobe:33025? ex act=title $\% 3 \mathrm{~A} \% 22 \mathrm{La}+$ Trobe + working + papers+in+linguistics.+Volume $+1+\% 28198$ 8\%29\%22 (accessed August 2010)

ALLAN Keith and BuRRIDGE Kate, Euphemism and Dysphemism: Language Used as Shield and Weapon, USA, Oxford University Press, 1991.

BACHE Carl, "Constraining conceptual integration theory: Levels of blending and disintegration", Journal of Pragmatics, Vol. 37 (10), Elsevier B.V. 2005: 1615-1635.

BarR Dale and Keysar Boaz, "Making Sense of How We Make Sense: Tha Paradox of Egocentrism in Language", in CoLSTON Herbert and KATZ Albert (Eds.), Figurative Language Comprehension: Social and Cultural Influences. Mahwah, NJ, Lawrence Erlbaum, 2005: 21-41.

BEAUGRANDE Robert de, "Poetry and the ordinary reader: A study in literary response", Empirical Studies in the Arts, Vol. 3, 1985: 1-21.

BLACK Max, Models and metaphors: Studies in language and philosophy, Ithaca: Cornell University Press, 1962.

Black Max, "More about Metaphor", in ORTONy Andrew (Ed.), Metaphor and Thought, Cambridge: Cambridge University Press, 1979.

BLUMENTRITT Tracie and HEREDIA Roberto, "Stereotype processing and non-literal language", in COLSTON Herbert and KATZ Albert (Eds.), Figurative Language Comprehension: Social and Cultural Influences, Mahwah, NJ: Lawrence Erlbaum, 2005: 261-281.

BoLINGER Dwight, Language - The Loaded Weapon: The use and abuse of language today, London and New York: Longman, 1980. 
BüHLER Karl, Theory of Language: The representational function of language, Amsterdam/Philadelphia: John Benjamins, 2011. [1934/1982; this edition translated by Donald Goodwin and Achim Eschbach]

CARTER Ronald, Language and Creativity.The Art of Common Talk, London and New York: Routledge, 2004.

Chamizo Domínguez Pedro, "Some Thesis on Euphemisms and Dysphemisms", in Zeszytynaukowe Uniwersytetu Rzeszowskiego Seria Filologiczna 25, Studia Anglica Resoviensia, Vol. 3, 2005: 9-16.

СномsкY Noam, Rules and Representations, Oxford: Basil Blackwell, 1980.

ClaRK Herbert and Haviland Susan, "Comprehension and the given-new contract", in FREEDlE Roy, (Ed.), Discourse production and comprehensio, Norwood, NJ: Ablex Publishing, 1977: 1-40.

Colston Herbert and KaTz Albert (Eds.), Figurative Language Comprehension: Social and Cultural Influences, Mahwah, NJ: Lawrence Erlbaum, 2005.

Crespo Fernández Eliecer, "Sex-Related Euphemism and Dysphemism: An Analysis in Terms of Conceptual Metaphor Theory", ATLANTIS. Journal of the Spanish Association of Anglo-American Studies, Vol. 30.2, 2008: 95-110.

Cruse Alan, Lexical Semantics, Cambridge: 'Cambridge Textbooks in Linguistics', Cambridge University Press, 1986.

Dnevnik newspaper 23 March 2010 at http://www.dnevnik.bg/bulgaria/2010/03/23/877570 zadurjani sa shestima ot lapachite nanesli shteti za/

DresSLER Wolfgang and MerLINI-BARBARESI Lavinia, Morphopragmatics: diminutives and intensifiers in Italian, German, and other languages, Berlin: Mouton de Gruyter, 1994.

Du BoIS John "Stance and Consequence", paper presented at the annual meeting of the American Anthropological Association, New Orleans, 2002.

DuRANTI Alessandro, Linguistic Anthropology, Cambridge: Cambrdige University Press, 1997.

Evans Vyvyan, "Towards a cognitive compositional semantics: An overview of LCCM Theory", in MAGNUSSON Ulf, KARDELAHenryk and GLAZ Adam (Eds.), Further Insights into Semantics and Lexicography, Lublin, Poland: Wydawnictwo UMCS, 2007: 1142.

Evans Vyvyan, How words mean: Lexical Concepts, Cognitive Models and Meaning Construction, Oxford: Oxford University Press, 2009.

Evans Vyvyan, "Figurative Language Understanding", Cognitive Linguistics, Vol. 21.4, 2010: 601-662.

FAuConnier Gilles and TURner Mark, The Way We Think: Conceptual Blending and the Mind's Hidden Complexities, New York: Basic Books, 2002.

FAUCONNIER Gilles, Mappings in thought and language, Cambridge: Cambridge University Press, 1997.

GEERAERTS Dirk, Theories of Lexical Semantics, Oxford: Oxford University Press, 2010.

GIBBS Raymond, Jr., The Poetics of Mind: Figurative Thought, Language, and Understanding, Cambridge: Cambridge Univeristy Press, 1994.

GIORA Rachel, "Understanding figurative and literal language: the Graded Salience Hypo thesis", Cognitive Linguistics 7.1, 1997: 183-206. 
GioRA Rachel, "Optimal innovation and pleasure”, in Sтоск Olivero, Carlo STRAPPARVA and Anton NijHolT (Eds.), Processing of The April Fools' Day Workshop on Computational Humour. April 2002, Trento, Italy: ITC-itst, 2002: 11-28.

GioRA Rachel, On Our Mind: Salience Context and Figurative Language, New York: Oxford University Press, 2003.

GLUCKSBERGSam, Understanding Figurative Language: From Metaphors to Idioms, Oxford: 'Oxford Psychology Series', Oxford University Press, 2001.

Gómez Casas, "Towards a new approach to the linguistic definition of euphemism", Language Sciences 31, 2009: 725-739.

Goossens Louis, "Metaphtonymy: The interaction of metaphor and metonymy in expressions for linguistic action", in DIRVEN René and Ralf PöRINGS, (Eds.), Metaphor and Metonymy in Comparison and Contrast, Berlin: Mouton de Gruyter, 2003: 349377.

GrozDanova Lilyana, Bulgarian-English Slang Dictionary, USA, McNeil Technologies, Dunwoody Press, 2010.

HALFORD Graeme and WILSON William, "Creativity, Relational Knowledge, and Capacity: Why Are Humans So Creative?", in DARTNALl Terry (Ed.), Creativity, Cognition, and Knowledge: An Interaction, Westport, CT: Praeger, 2002: 153-180.

HallidaY Michael, An Introduction to Functional Grammar, London: Edward Arnold, 1994 (second edition).

HaLlidaY Michael, Learning how to mean, London: Edward Arnold, 1975.

Hamilton David, Stroessner Steven and Driscoll Denise, "Social cognition and the study of stereotyping", in Devine Patricia, Hamilton David and Ostrom Thomas (Eds.), Social cognition: Impact on social psychology, San Diego, CA: Academic Press, 1994: 291-321.

Holder R. W., How not to Say What You Mean: A Dictionary of Euphemisms, New York: Oxford University Press, 2007 (4th edition) [1987].

HougaARD Anders, "Conceptual disintegration and blending in interactional sequences: A discussion of new phenomena, processes vs. products, and methodology", Journal of Pragmatics, Vol. 37.10, 2005: 1653-1685.

HUANG Mimi, "Solving the riddle of metaphor: A slience-based model for metaphorical interpretation in a discourse context", in Evans Vyvyan and POURCEL Stéphanie (Eds.), New Directions in Cognitive Linguistics, Amsterdam/Philadelphia: 'Human Cognitive Processing" 24, John Benjamins, 2009: 107-126.

JURAFSKY Daniel, "Universal Tendencies in the Semantics of the Diminutive", Language, 72 (3): 533-578.

KATZ Albert, "Discourse and Socio-cutural Factors in Understanding Nonliteral Language" in COLSTON Herbert and KATZ Albert (Eds.), Figurative Language Comprehension: Social and Cultural Influences, Mahwah, NJ : Lawrence Erlbaum, 2005: 183-207.

KEARNEY Richard, The Wake of Imagination: Ideas of Creativity in Western Culture, London: HarperCollins, 1998.

KoESTLER Arthur, The Act of Creation, London: Hutchinson, 1964.

KöVECSES Zoltán, "Metaphor and Emotion", in GIBBS Raymond W, Jr. (Ed.) The Cambridge Handbook of Metaphor, Cambridge: Cambridge University Press, 2008: 380-396. 
KRYK-KASTOVSKY Barbara, "Diminutives: An Interface of word-formation, semantics and pragmatics", in DALTON-PUfFER Christiane and RITT Nikolaus (Eds.), Words: Structure, meaning, function. A festschrift for Dieter Kastovsk, Berlin/New York: Mouton de Gruyter, 2000: 165-174.

LAKOFF George and TURNER Mark, More than cool reason, Chicago: University of Chicago Press, 1989.

LAKOFF George and JoHnson Mark, Metaphors we live by, Chicago: University of Chicago Press, 1980.

LANGLOTZ Andreas, Idiomatic Creativity: A Cognitive Linguistic Model of IdiomRepresentations and Idiom-Variation in English, Amsterdam and Phildelphia: John Benjamins, 2006.

LiPPMANN Walter, Public Opinion, New York: Harcourt, Brace, 1922.

MALRIEU Jean Pierre, Evaluative Semantics: Cognition, Language, and Ideology, London: Routledge, 1999.

MARTIN James, "Beyond Exchange: APPRAISAL Systems in English", in Hunston Susan and Thompson Geoffrey (Eds.), Evaluation in Text: Authorial Stance and the Construction of Discourse, Oxford: Oxford University Press, 2000, 142-178.

MARTIN James and WHITE Peter, The Language of Evaluation. Appraisal in English, Hampshire and New York: Pelgrave McMillan, 2005.

MCGLONE Matthew, "Concepts as Metaphors", in GluCKSBERG Sam (Ed.), Understanding Figurative Language, Oxford: Oxford University Press, 2001: 90-107.

MCGlone Michael, GluCKSBERg Sam and CACCIARI Cristina, "Semantic productivity and idiom comprehension", Discourse Processes, Vol. 17, 2, 1994: 169-90.

MILLER Arthur, "Historical and contemporary perspectives on stereotyping", in MILLER Arthur, (Ed.), In the eye of the beholder: Contemporary issues in stereotyping, New York: Praeger, 1982: 1-40.

MuNAT Judith, "Creation or recreation? Word formation processes and word creation strategies as components of lexical creativity", in So RLIN Sandrine (Ed.), Inventive Linguistics, Montpellier: Presses Universitaires de la Méditerranée, 2010: 147-157.

MunAT Judith (Ed.), Lexical Creativity, Texts and Contexts, Amsterdam and Philadelphia: John Benjamins, 2007.

OCHS Elinor (Ed.) Text 9 (1) (special issue on the pragmatics of affect), 1989.

OXFORD ENGLISH DiCTIONARY, Second edition on CD-ROM Version 4.0. Oxford University Press, 2009.

Panther Klaus-Uwe and Thornburg Linda, "Metonymy", in GeERAERTS Dirk and CuYCKENS Hubert (Eds.), Oxford Handbook of Cognitive Linguistics, New York: Oxford University Press, 2007: 236-263.

PANTHER Klaus-Uwe and THORNBURG Linda, "Introduction: On the nature of conceptual Metonymy", in Panther Klaus-Uwe and Thornburg Linda (Eds.), Metonymy and Pragmatic Inferencing, Amsterdam: John Benjamins, 2003: 1-20.

Pfaff Kerry, GibBS Raymond and Johnson Michael, "Metaphor in using and understanding euphemism and dysphemism", in Applied Psycholinguistics 18, 1997: 59-83.

PINKER Steven, The Stuff of Thought: Language as a Window into Human Nature, London: Penguin Books, 2008 [2007]. 
REDDY Michael, "The conduit metaphor - a case of frame conflict in our language about language" in ORTONY Andrew, (Ed.), Metaphor and thought, Cambridge: Cambridge University Press, 1979: 284-297.

RICHARDS Ivor, The Philosophy of Rhetoric, Oxford: Oxford University Press, 1936.

RICOEUR Paul, "The creativity of language", in BURKE Lucy, CROWLEY Tony and GIRVIN Alan (Eds.), The Routledge Language and Cultural Theory Reader, London: Routledge, 2000 [1981]: 340-344.

RuIZ DE MENDoza Ibáñez Franscico "Some notes on the grammatical status of the Spanish -ito/-illo diminutives and their translation in English", Pragmalingüística 3-4, Universidad de Cádiz, 1995-1996: 155-172.

SÁENZ Francisco, "Conceptual Interaction and Spanish Diminutives" in C. I. F., XXV, 1999: 173-190.

SCHNEIDER David, The Psychology of Stereotyping, New York: Guilford Press, 2004.

SILVERSTEIN Michael, "Shifters, Linguistic Categories, and Cultural Description", in BASSO Keith and SElBy Henry (Eds.), Meaning in Anthropology, Albuquerque: University of New Mexico Press. 1976: 11-56.

SINGER Marshal, Perception and Identity in Intercultural Communication, Yarmouth, ME., Intercultural Press, 1998.

SLOBIN Dan, (2005) Thinking for speaking. In QUALIA 2, jaargang 2. at http://ihd.berkeley.edu/Slobin-

Language \%20\&\%20Cognition/\%282005\%29\%20Slobin \%20\%20Thinking\%20for\%20speaking\%20\%28Qualia\%20interview\%29.pdf (accessed March 2011)

SMith Eliot and SEMIN Gün, "Situated social cognition", Current Directions In Psychological Science, Vol., 16, 2007: 132-135.

Tannen Deborah, "Frames Revisited", Qaderni di Semantica, Vol.VII/1, 1986: 106-109.

TENDAHL Markus, A Hybrid Theory of Metaphor: Relevance Theory and Cognitive Linguistics, Palgrave: Macmillan, 2009.

Thibault Paul, Brain, Mind, and the Signifying Body: An Ecosocial Semiotic Theory, London and New York: Continuum 2004.

TOMASEllo Michael, Constructing a Language: A Usage-Based Theory of Language Acquisition, Harvard University Press, 2003a.

Tomasselo Michael, "The Key Is Social Cognition", in GENTnER Dedre and Goldin-MEdow Susan (Eds.), Language in Mind: Advances in the Study of Language and Thought, Cambridge, Massachusetts, the MIT Press, 2003b: 47-57.

WiERzBicKA Anna, "Diminutives and depreciatives: Semantic representation for derivational categories", Quaderni di Semantica, Vol. 5, 1984: 123-130.

WierzBiCKA Anna, Cross-cultural Pragmatics. The Semantics of Human Interaction, Berlin: 'Trends in Linguistics. Studies and Monographs 53', Mouton de Gruyter, 1991.

Wierzbicka Anna, "Back to definitions: Cognition, semantics, and lexicography, Lexicographica, Vol. 8, 1992: 146- 174.

YEH Wenchi and BARSALOU Lawrence, "The Situated nature of concepts", American Journal of Psychology, Vol. 119, 3, 2006: 349-384.

ZAWADA Brita, "Linguistic creativity from a cognitive perspective", Southern African Linguistics and Applied Language Studies, Vol. 24 (2), South Africa, NISC Pty Ltd 2006: 235-254. 
ZLATEV Jordan, Situated Embodiment: Studies in the Emergence of Spatial Meaning. Gotab: Stockholm, 1997.

ЗидАРовА Ваня, (2008) Деминутиви и лексикална номинация (at http://www.belb.net/personal/zidarova/deminutiva_lex.htm). [Zidarova, V. (2008) Diminutives and Lexical Nomination) (accessed May 2010).

ЗидАровА Ваня, (2005) Лексикализация на деминутивите в съвременния български книжовен език. In Стоя нова, Ю, Дачева, Г., Павлова, Н., Михайлова, Н и Миланов, В. (съст.) Littera Scripta Manet. Сборник в чест на 65годишнината на проф. дфн Василка Радева. София, Университетско издателство „Св. Климент Охридски“. [Stoyanova, Yu., Dacheva, G., Pavlova, N., Mihayilova, N. and Milanov, V. (eds.) Papers in Honour of Vasilka Radeva. Sofia: Univeristy Publishing House "St. Kliment Ohridski"]: 601-608.

ПЕРнишкА Емилия, (ред.) Речник на новите думи в българския език, София, Наука и изкуство, 2010 [PERNISHKA Emiliya, (Ed.), Rechnik na novite dumi v balgarskiya ezik, Dictionary of new words in Bulgarian, Sofia, Nauka i izkustvo, 2010].

ПЕРнишкА Емилия, (ред.) Речник на новите думи и значения в българския език, София, Наука и изкуство, 2010 [PERNISHKA Emiliya, (Ed.), Rechnik na novite dumi I znacheniya $\mathrm{v}$ balgarskiya ezik, Dictionary of new words and meanings in Bulgarian, Sofia, Nauka i izkustvo, 2001]. 